\title{
COMMENTARY
}

\section{Impact of Coronavirus disease 2019 on macroeconomics and overall development in the Democratic Republic of Congo}

\author{
Oscar N. Luboya ${ }^{1,2,3}$ Olivier Mukuku ${ }^{1^{*}} \quad$ Léon N. Kabamba $^{4}$ Augustin M. Mutombo $^{3}$ Paul M. Mawaw $^{2}$ \\ ${ }^{1}$ Institut Supérieur des Techniques Médicales de Lubumbashi, Lubumbashi, Democratic Republic of Congo \\ ${ }^{2}$ Department of Public Health, Faculty of Medicine, University of Lubumbashi, Democratic Republic of Congo \\ ${ }^{3}$ Department of Pediatrics, Faculty of Medicine, University of Lubumbashi, Democratic Republic of Congo \\ ${ }^{4}$ Department of Public Health, Faculty of Medicine, University of Kamina, Democratic Republic of Congo
}

\section{Check for updates}

Correspondence to: Olivier Mukuku, Institut Supérieur des Techniques Médicales de Lubumbashi, Lubumbashi, Democratic Republic of Congo;

E-mail: oliviermukuku@yahoo.fr

Received: November 26, 2020;

Accepted: December 29, 2020;

Published: December 30, 2020

Citation: Luboya ON, Mukuku O, Kabamba LN, et al. Impact of Coronavirus disease 2019 on macroeconomics and overall development in the Democratic Republic of Congo. Adv Gen Pract Med, 2020, 3(1): 26-27.

https://doi.org/10.25082/AGPM.2020.01.003

Copyright: (C) 2020 Olivier Mukuku, et al. This is an open access article distributed under the terms of the Creative Commons Attribution License, which permits unrestricted use, distribution, and reproduction in any medium, provided the original author and source are credited.

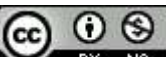

\section{Introduction}

Health system can be defined as all the human, organizational, structural and financial resources intended to achieve the objectives of a health policy [1]. It is a subsystem of the general economic development of a country along with agriculture, education, mining, fishing, and many others [2,3]. As such, it is in constant interaction with other subsystems in terms of allocating the resources necessary for its operation.

Any health system must be firmly based on the following elements: adequate organization, structures adapted to its health policy, materials and competent people. An ideal health system includes the following qualities:

(1) Comprehensiveness covering all sectors with particular emphasis on preventive activities;

(2) Provision of care and services favouring equity;

(3) Accessibility in its 3 dimensions: geographic, economic or financial and informational.

Every health system should be effective and efficient both economically and technically. The health system must also be acceptable to the population and therefore respond to its current and or potential problems. As such, it should have its own identity and would avoid being a copy of a system from other countries, as policies and health issues are not themselves easily superimposed. Planning and system assessment based on specific realities must characterize any national system.

Finally, the health system must be flexible and modifiable to adapt to new situations imposed by a whole new type of morbidity, unexpected emergency or improvised socio-economic conditions. Despite the socio-cultural diversity of different systems, there is, however, a common denominator on which they are all very firmly based: ensuring equal access to care, and the effectiveness and efficiency of care provided to the responsible population.

\section{Role of Coronavirus disease 2019 on the Congolese health system}

The epidemic caused by coronavirus disease 2019 (COVID-19), which started in China, quickly spread around the world, becoming a global pandemic. It strikes rich and poor without spread, causing high morbidity and mortality in all continents. This disease known starting to affect the lungs is today ranked among the pathologies affecting systematically all the human bodies. While the majority or nearly all countries are affected, apparently there is no country whose health system was specifically prepared to respond properly to this pandemic for its effective and efficient control. 
Thus the pandemic has upset almost everywhere it has happened, the scale of health priorities; this is an illusion in the eyes of many decision-makers. Indeed, a study based on the causes of deaths from January 1st to May 11th, 2020 gives the order descending ranking following worldwide: infectious diseases, malnutrition, cancer, road traffic accidents, suicides, malaria and COVID-19, which is not among the top five deadliest problems according to the World Health Organization and the United Nations.

On the ground in the Democratic Republic of Congo, COVID-19 has found a health system weakened by outbreaks of other epidemics such as measles, polio, yellow fever, rubella, Ebola and cholera. Preventive measures of distancing and recommended barriers push the system further into the underuse of curative and preventive care services. The first line seems to be forgotten in favor of second and third level hospitals. The health district management team does not appear to be adequately involved in the monitoring which further verticalizes this health problem. Insufficient drugs and other specific materials are felt in many places where most health zones are no longer properly supervised, further crippling the national health system. Health provides individuals and families with the prospect of personal development and the possibility of ensuring their economic security in the future.

Health is economically one of the two pillars of human capital for its overall development. Good health for a community generates economic wealth and thus contributes to poverty reduction and economic growth [1-4]. Real revolution in the field of public health by fighting against diseases and ensuring proper nutrition improve worker performance and reduces the suffering of the working population. Preventable diseases are a vicious circle because they require a high investment cost, while their presence significantly reduces the annual income of a country.

From a macroeconomic point of view, countries with alarming health and education indicators have great difficulty in achieving significant economic growth; this is revealed by the impact of COVID-19 around the world.

Other sectors or elements of the great overall development system are not also spared. The economic sector has alarming indicators. Education is at idle, trade is now in red and all of these are closely related.

\section{Conclusion}

The COVID-19 pandemic has demonstrated that no country has a perfect health system. The negative impact or dysfunction of the health sector has systematically led to the other elements of overall development. For our country, this unfortunate case should encourage us more to invest in the health sector after the passage of COVID-19.

\section{References}

[1] Cazaban M, Duffour J and Fabro-Paray P. Santé Publique, 5è édition, Paris: Masson, 2005.

[2] WHO Commission on Macroeconomics and Health. Macroéconomie et santé: investir dans la santé pour le développement économique : rapport de la Commission Macroéconomie et Santé. Genève: Organisation mondiale de la Santé, 2001. https://apps.who.int/iris/handle/10665/43613

[3] Kremer M. Public policies to stimulate development of vaccines and drugs for neglected diseases. In Banerjee AV, Bénabou R, Mookherjee D (Eds). Understanding poverty. New York: Oxford University Press, 2006.

[4] Bouyer J, Hémon D, Cordier S, et al. Epidémiologie : Principes et méthodes quantitatives. Paris: Lavoisier, 2009. 